\title{
Las puertas abiertas: continuidad, obsolescencia y potencialidad en la literatura y el arte recientes
}

\author{
The open doors: continuity, obsolescence and \\ potentiality in recent literature and art
}

\author{
BETINA KEIZMAN \\ Universidad Alberto Hurtado. Departamento de Literatura. \\ Correo electrónico: bkeizman@uahurtado.cl
}

Este trabajo pone en diálogo una serie de obras del artista plástico argentino Adrián Villar Rojas y la novela Opendoor (2006) del escritor Iosi Havilio en torno a la exploración del horizonte fallido del progreso y de la evolución, lo que se rescata, el anacronismo y lo que permanece, es decir, nociones de obsolescencia, extinción y continuidad. Tanto Villar Rojas como Havilio trastornan, en primer término, las temporalidades, pero también espacios y subjetividades que la modernidad concibió ligadas a un sujeto central que, abandonado a sus propias potencias, se descubre poroso respecto de los otros, de la naturaleza y de los objetos. En el caso de Opendoor, el territorio transurbano o transrural y la comunidad transgeneracional amparan rangos de experiencia que escapan de las mallas de contención y administración del tiempo. Las puertas abiertas de la novela de Havilio lo son entre el espacio rural y el urbano; las obras de Villar Rojas trasladan la naturaleza a espacios urbano, o superponen espacios naturales y museísticos. Ambos exploran tránsitos de órdenes múltiples y de vidas potenciales.

Palabras claves: Villar Rojas, Iosi Havilio, vidas potenciales, temporalidades, transurbano.

This work settle a dialog between a series of pieces from the Adrián Villar Rojas Argentinian plastic artist and the novel Opendoor (2006) from the Iosi Havilio writer around the exploration of the failed horizon of progress and evolution, anachronism and what remains, namely, notions of obsolescence, quenching and continuity. Both Villar Rojas and Havilio questions the modern logic of temporality, space and subjectivity, which now discovers itself pervious compared to others, nature and objects. In Opendoor, the transurban or transrural territory and the transgenerational community shelter a range of experiences that escape out time retaining and administrating net. In Havilio novel's "open doors" separate rural and urban space, but also dig into potential lives.

Key words: Villar Rojas, Iosi Havilio, potential lives, temporalities, Transurban.

\footnotetext{
*Este artículo forma parte del Proyecto regular FONDECYT No 1170129 (2017-2020), Universidad Alberto Hurtado: "Perspectivas ampliadas: formas de vida, comunidad y poética en las narrativas contemporáneas en Chile, México y Argentina”.
} 
Durante los últimos años la imaginación contemporánea ha nutrido con nuevo ímpetu la especulación en torno a mundos apocalípticos, post-apocalipticos y "reinicializados" (en el ámbito de la literatura latinoamericana contribuyen a este conjunto, entre otros, El año del desierto de Pedro Mairal, Cataratas de Hernán Vanoli, El animal sobre la piedra de Daniela Tarazona, Gongue de Marcelo Cohen y Vidas perpendiculares de Álvaro Enrigue). Son narrativas que ponen en escena universos estéticos en que el encuentro entre cultura y naturaleza poco y nada contribuye a una organización de diferencias radicales. Muy al contrario, se disipan oposiciones canónicas en favor de lo viviente confundido y, más importante aún, se reelaboran los términos de la obsolescencia y de la extinción, es decir de lo que entra en el circuito de desuso (un término fundamental en la economía global contemporánea) o de directa desaparición (también aquí una categoría cada vez más relevante en un mundo en el que la biodiversidad exige una creciente protección). Para completar el corpus literario que menciono con artistas visuales cuyo trabajo también se desarrolla en este ámbito, he aquí los nombres de Ignacio Agüero y Lisandro Alonso, en cine; Marcelo Pombo, Nicola Costantino y Carlos Huffmann, en artes visuales. Las prácticas de estos artistas visuales y de estos narradores relegan las imágenes y narrativas del progreso, esos argumentos de líneas evolutivas, sean colectivas o individuales, que alineadas por una progresión ascendente fundaban, incluso con puntos de conflicto, algún grado de certeza de una evolución tecnológica, histórica, social y humana, o aquellos otros, que podían aspirar a una equívoca estampa de un todo social. Lo que se abre paso son obras muy diferentes, más erráticas en sus disposiciones, que ponen en acción subjetividades en deriva; creaciones que imbrican los reinos animales y vegetales, terrestres y humano; imaginaciones que articulan intrincados vínculos entre lo global y lo local, desplazando categorías de centralidad y periferia, y que colocan a sus "receptores" en un estado más cercano a la indeterminación activa que a una recepción estética asertiva que los reafirme en sujetividades canónicas. En este trabajo propongo indagar bajo esta perspectiva algunas obras del artista Adrián Villar Rojas, explícitamente ligadas al imaginario que estoy convocando, y Opendoor (2006), una novela del escritor argentino Iosi Havilio en que estas fuerzas imaginativas aparecen atenuadas, en baja tensión, pero que por eso mismo interesa examinar, porque ese estado liminar de las subjetividades en deriva a la que aludo reafirma hasta qué grado estos problemas y estas búsquedas permean el arte contemporáneo.

El corpus de obras de Villar Rojas al que voy a referirme tiene, en su diversidad, algunos elementos en común. En su mayor parte la superficie exterior de las obras está hecha de arcilla sin coser. Lo que se representa son formas animales, seres mutantes ensamblados de partes de animales reconocibles, algunas figuras humanas despojadas y atemporales, formas orgánicas o tecnológicas, montajes de virus o células agigantadas con posibles herramientas de tecnologías avanzadas. La conmoción que generan las obras emana de la intersección entre los tamaños, en su mayor parte agigantados, la materia y la condición misma de los seres que se representan. My Dead Grandfather (2010) es una escultura gigante $(500$ × 2300 × $400 \mathrm{~cm})$ que fue emplazada en la Akademie der Kunste de Berlin. Es un monstruo o dinosaurio marino, una variante de ballena espinosa que yace en un parque, 
a medias aferrada a un árbol real ubicado entre muros y galerías. En la paradójica filiación con lo humano que subraya el título de la obra hallamos el mismo gesto que se replica en Una persona me amó (2012), construida con el mismo material arcilloso y que representa una figura entre telescopio y virus agigantado. Los títulos señalan el vínculo dudoso, pero finalmente asertivo, entre lo humano y estas figuras mutantes. Por otra parte, la materia de la arcilla produce múltiples efectos. De alguna manera acentúa el carácter de antigüedad, la impresión de fósil terreo que emana de las obras. Además, mediado por pautas culturales que ligan arcilla y creación primigenia, insinúa este orden de lo inicial de un mundo que vuelve al origen, pero en su regreso se concede la experimentación visual y material de otras formas de vida, de otras combinaciones y otros sustentos culturales y tecnológicos. La tensión entre los nombres de las obras y aquello que representan también evidencia órdenes de afectividad, el amor y los ancestros. Pone en primer plano un tenor emocional que el espectador no ignora.

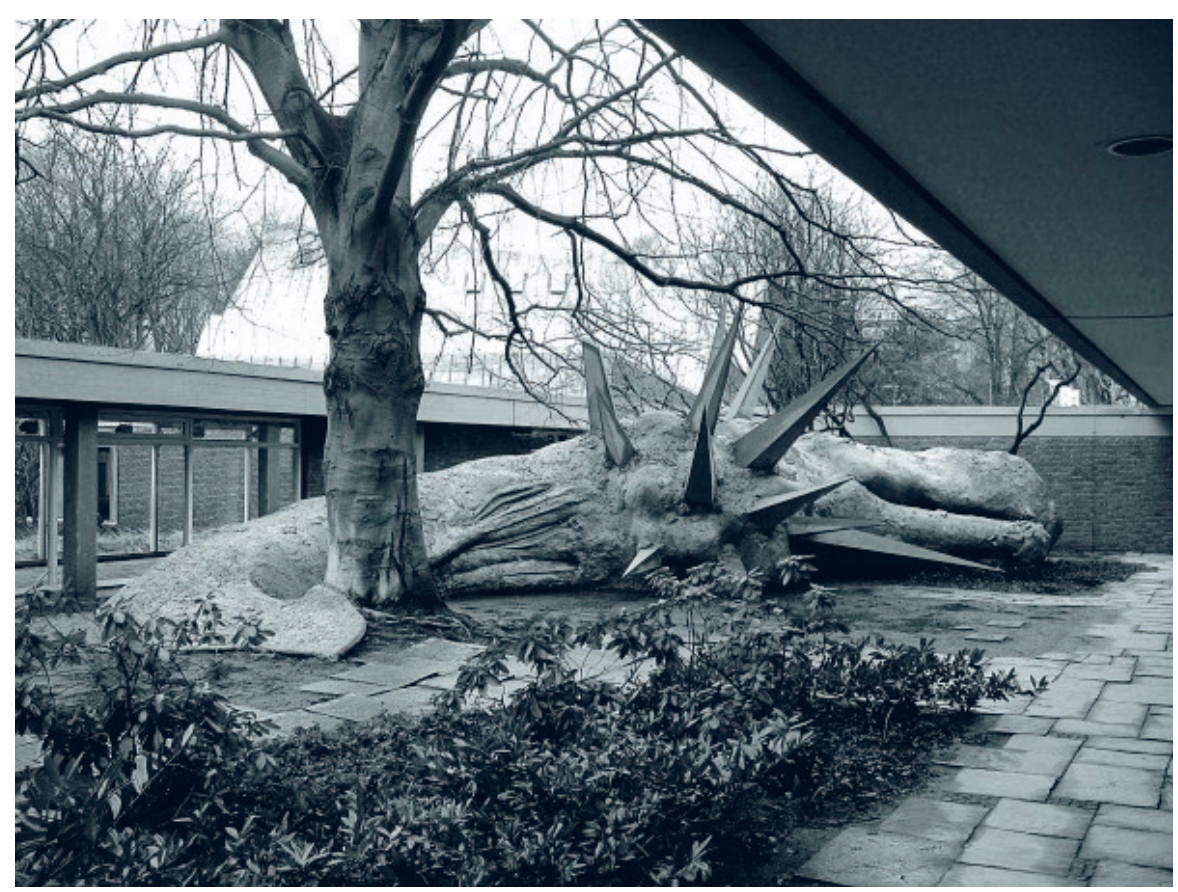

Fig. 1. My Dead Grandfather/ 2010

Site specific sculpture/Clay (unfired), cement, burlap and wood $500 \times 2300 \times 400 \mathrm{~cm}$

Akademie der Kunste, Berlin, Germany 

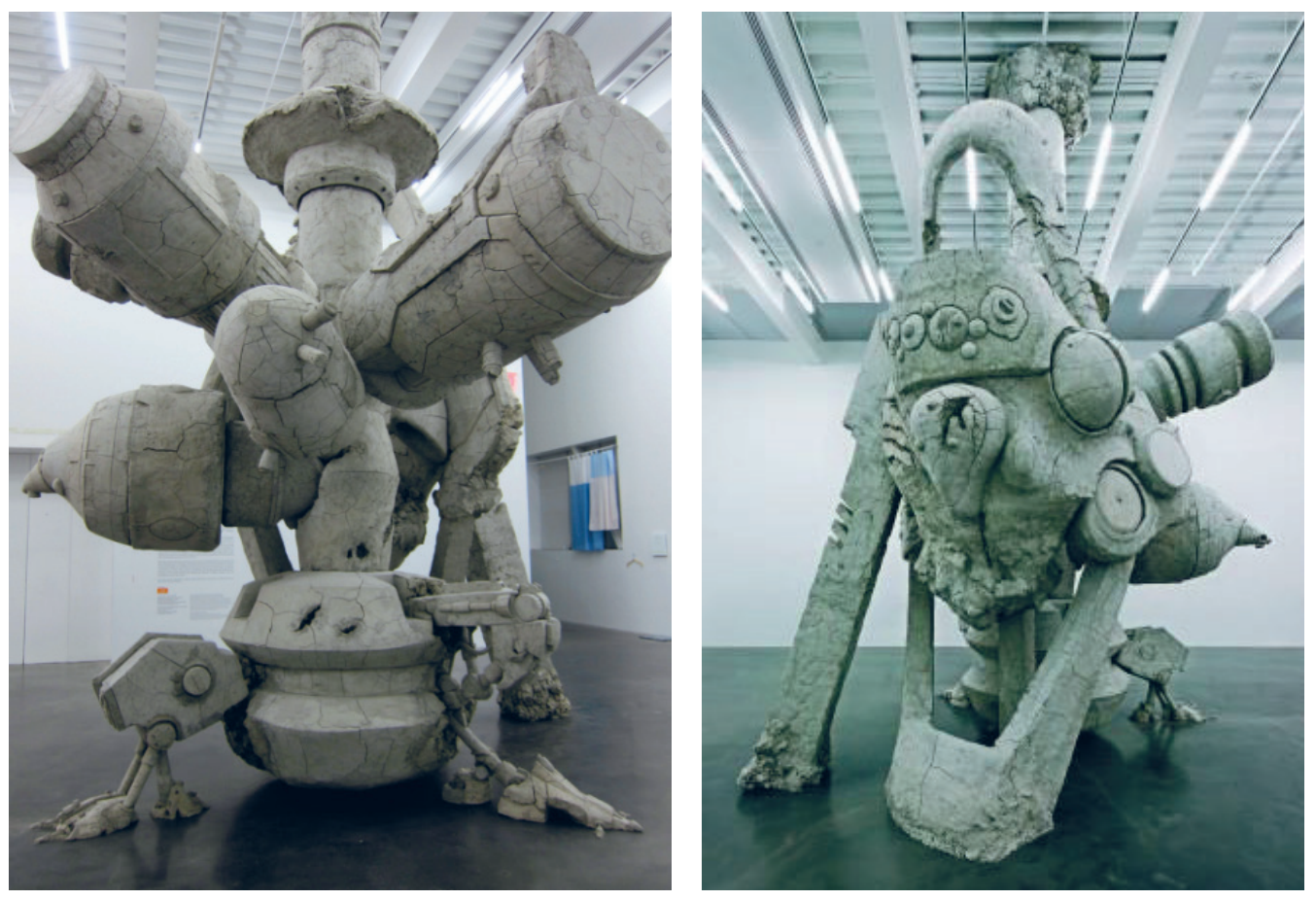

Fig. 2. Una persona me amó / 2012

Escultura -site specific- Arcilla (sin cocer), madera, cemento, metal, espuma de poliestireno /

$750 \mathrm{~cm} \times 500 \mathrm{~cm} \times 500 \mathrm{~cm}$

The Ungovernables en el New Museum, Nueva York, USA

En el caso de Today We Reboot the Planet, cuyo título tiene resonancia con las tecnologías contemporáneas siempre prestas a "reinicializar", es una exposición que exhibió, entre otros, un conjunto de piezas expuestas sobre estantes de vidrio, es decir, que la instalación replica de modo directo la exhibición de un museo de ciencias naturales o geológicas. También aquí, aunque en menor tamaño, Villar Rojas insiste en la estética de la pieza arqueológica o geo-biológica. 


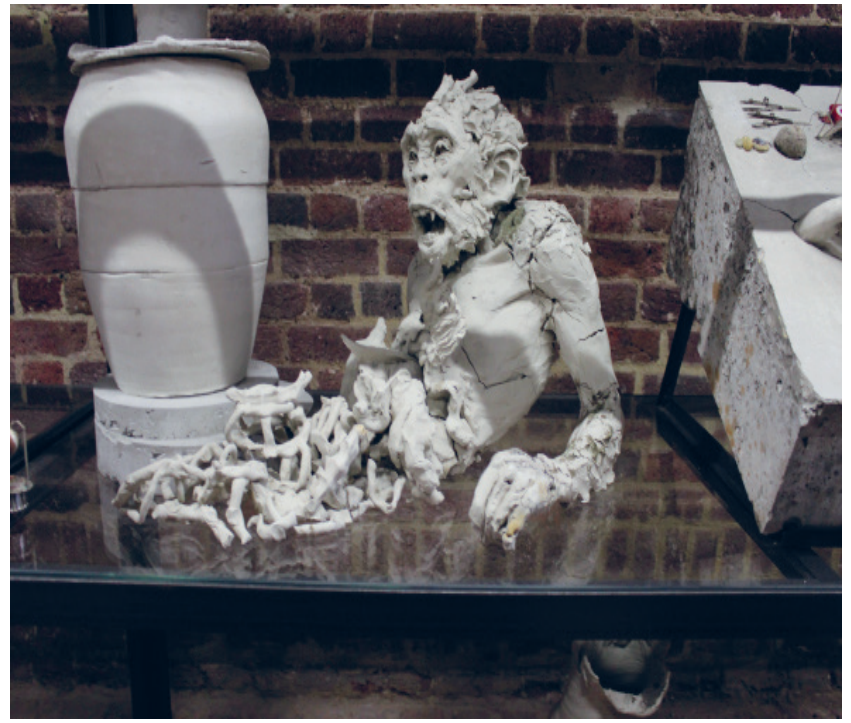

Fig. 3. Today We Reboot the Planet/ 2013

Arcilla (sin cocer), madera, cemento, metal

Vista de exposición la Serpentine Sackler Galería, Londres. Septiembre 2013

Estas obras de Villar Rojas son inquietantes en relación con la temporalidad en que se inscriben, pero también por la manera en que instalan una incógnita: ¿son animales, son piedra o tierra, pertenecen al pasado o al futuro, cuál es el vínculo que tienen con el sujeto humano, qué tipo de colección están exhibiendo y cuál es la genealogía a la que con tanta insistencia aluden? Al definirlos como colección (una colección que se organiza bajo la firma unificadora de artista) remontan como objeto fósil, elección y residuo, en la medida en que cualquier objeto que se introduce en el archivo de una colección es, ante todo, un objeto recuperado, elegido en el magma de lo que, a partir de ese momento, se proyecta hacia lo indiferenciable. Nunca se podrá saber si estas obras aluden a un pasado extinto o a un futuro posible, también podrían abrirse a una experiencia de otro orden, una existencia virtual, potencial y vitalizadora, tal como la concibe Deleuze cuando opone lo virtual a lo actual (y no a lo real), puesto que lo virtual es lo que puede devenir, una línea de fuga, ni real ni imaginaria, y que compete particularmente al arte: "un porvenir no es imaginario, como tampoco un viaje es real. El devenir es lo que convierte el trayecto más mínimo, o incluso una inmovilidad sin desplazamiento, en un viaje; y el trayecto es lo que convierte lo imaginario en un devenir. Los dos mapas, el de los trayectos y el de los afectos, remiten uno al otro" (Deleuze 1996: 94). La ruina y el escombro, parte sustancial del imaginario de Villar Rojas, es leída por Graciela Speranza bajo la clave de las cronografías, articulaciones de "un presente disparado a otros tiempos" (Speranza 2017: 17), es decir 
como reconfiguración de nuestra experiencia del tiempo: "La potencia irreductible de la imaginación artística sigue cifrando en sus formas metáforas del presente y anticipaciones del futuro, y atisbando configuraciones todavía inaccesibles a otros lenguajes" (Speranza 2017: 20). En la lectura de Graciela Speranza, la obra de Villar Rojas especula un mundo reinicializado (como he señalado anteriormente, el título de una de sus exposiciones), en que se reencuentran cultura y naturaleza, lo viviente confundido en un tiempo ampliado que podría ser el pasado o el futuro, pero que se instala en el presente de la exposición.

Por otra parte, tampoco es errado suponer que estas configuraciones de lo animalhumano-objetual constituyen agentes, en el sentido en que lo propone Graham Harman en su lectura de Bruno Latour, es decir, ni sujetos ni objetos. Son instalaciones que involucran un orden de materialidades libradas a coexistencias precarias: formas vitales agrandadas, mutantes terrosos, representaciones de vidas posibles o pasadas, vidas potenciales, figurasred que atrapan dimensiones imprevistas de la existencia, de la vida y de los saberes como si allí se sedimentara y recuperara un cúmulo de experiencias ligado a las rebarbas y residuos de condiciones, materias y posibilidades que fueron descartados, reprimidos o simplemente empujados a la retaguardia en la hora de la conformación de los saberes de la modernidad.

Las obras de Villar Rojas se disponen en grandes volúmenes aunque, como ya he señalado, algunas amplían figuras que remiten a formas vitales mínimas, una ontología dudosa de virus agigantados o módulos tecnológicos mutantes. Si algo generan estas instalaciones, es una desbordante sensación de "fuera de lugar", porque aquello que está sometido a la obsolescencia, al residuo y a la extinción siempre está, en alguna medida, "fuera de lugar", incluso si ha sido elegido, ha atravesado el tiempo y aparece, después de esta operación científica-mágica-creativa, inserto en una nueva serialidad. Sin embargo, la eficacia emotiva de las imágenes regresa como un boomerang: ¿cómo algo tan grande, tan antiguo, tan sustancial en la fuerza del afecto que motiva su mera presencia podría estar "fuera de lugar"? Esta eficacia emotiva se fija en la noción de lo que llamo "viviente confundido", y en los modos en que esto viviente involucra a cualquier espectador por la vía de la identificación o del desconcierto. La réplica de escenas iniciales, como es el caso de Devolver el mundo, dialoga con relatos míticos de la fundación de civilizaciones como la romana, pero es un cordero, o tal vez un cerdo, en que en este caso bebe del seno de una mujer, como una imagen especular del bebé humano abandonado que se alimenta de las ubres de una loba o de otro animal. En esta obra, la vitalidad y el don de la vida atraviesan las especies de tal modo que quedan ligadas no solo por la nutriente sino por el afecto del gesto y del compromiso, por una continuidad de las carnes. 


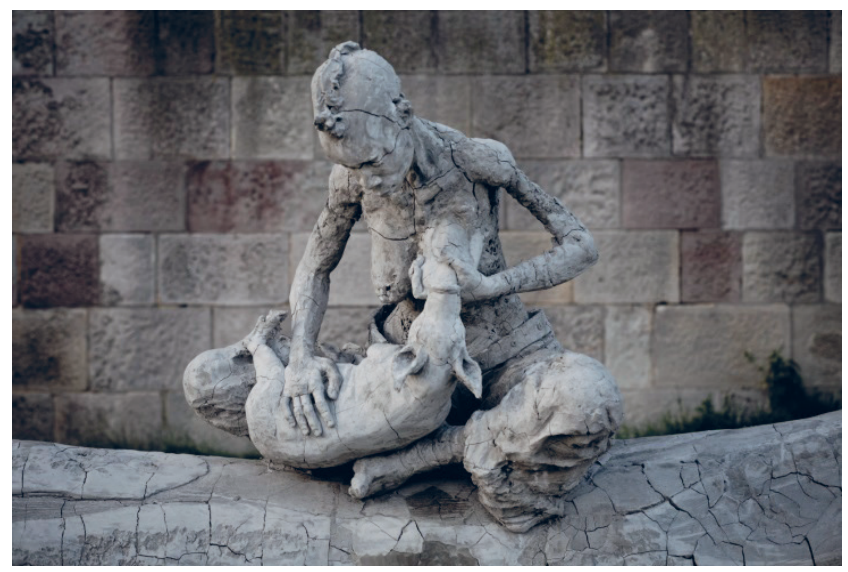

Fig. 4. Devolver el mundo. 2012

Escultura -site specific- Kabul

Clay (sin cocer), madera, arpillera $24000 \times 600 \times 80 \mathrm{~cm}$

Jardines Baghe Babur, dOCUMENTA (13) Kabul, Afganistán

Las obras apuestan a la teatralidad propia de toda exhibición, fuerzan un carácter de situación in media res que al apelar a algún tipo de ontología de lo viviente nos involucra en el sentido más comprometido, por ser habitantes del mundo, por humanos y por seres vivos. ¿Pero cuál es ese mundo que las obras devuelven? Hay un vaivén entre lo que se revela como real, profundo y cierto versus el carácter fantástico y espectral de estas figuras de tonos monocordes de fósil. El fósil es lo extinto que regresa, conserva una información guardada en su materialidad, una temporalidad cifrada. Pero en definitiva todo aquello con lo que interactuamos pertenece a un tiempo anterior, siguiendo la hipótesis de Alfred North Whitehead, tal como la sintetiza Graham Harman cuando señala que "sea lo que sea que prehendemos de otra entidad, tiene que ser solo lo que, en ella, ya ha pasado: la objetivación nos llega luego de una postergación indefinida” (Harman 2015: 34). Vale decir que las obras de Villar Rojas estarían expresando materialmente este retroceso temporal que es el propio de cualquier prehensión, un término que Harman propone para suplantar y exceder la aprehensión, que atribuye a la subjetividad humana un rol central que la corriente materialista le niega. El individuo que percibe o aprehende, también él está sometido a la prehensión del objeto. Incluso podríamos ir más lejos, recordar, como he dicho más arriba, que obsolescencia y extinción son dos categorías fundamentales de la vida contemporánea, dos zonas tensionadas por la lógica productiva de la economía global que tiene uno de sus motores en la obsolescencia programada y que se abisma, siempre sin poder detenerse, ante la amenaza de la extinción. La extinción misma adquiere nuevos significados en las 
obras de Villar Rojas, para comenzar nunca es absoluta, sino que se introduce en cadenas de transformaciones, en una condición de inestabilidad a la que las obras también aluden.

Atendiendo a otro aspecto, el impacto de la instalación paisajística de estas obras estimula una mirada panorámica que se adecue a estas escalas. El gran formato requiere de una distancia para apreciar el conjunto o para ponerlo en perspectiva, una mirada que, desde la reflexión de Latour y su trabajo con las redes, se corresponde con la complejidad de sistemas mixtos, múltiples, más amplios que el recorte que lo disciplinar instala junto con sus presupuestos a la hora de evaluar un problema. Lo que la noción de red pone en evidencia, según Latour, son las tramas heterogéneas entre elementos animados e inanimados en un entorno de indiferenciación entre lo social y lo técnico, en que los procesos técnicos y sociales se influyen y se construyen simultáneamente, en que lo humano y lo no-humano activa una coexistencia que no admite desprendimientos. En un sentido que excede la situación de exposición, los objetos de Villar Rojas son figuras-red que cruzan lo mítico, lo biológico, lo artístico, lo material, lo metafórico, lo humano, lo animal, lo arqueológico y lo pétreo; pero también lo son porque ponen en funcionamiento todas esas dimensiones en el encuentro con la mirada y la sensibilidad del espectador. La posición que hay que adquirir para verlas exige una distancia para apreciar el conjunto, pero también fuerza una coexistencia afectiva que incluye al espectador y lo introduce en la experiencia, una intimidad que no se ancla en las subjetividades sino en la reverberación emocional de un encuentro misterioso.

\section{LAS PUERTAS ABIERTAS}

A partir del foco inicial de esta reflexión quiero aproximarme a Opendoor de Iosi Havilio bajo una perspectiva afín. Como hemos dicho, un punto de encuentro en la creación de los dos artistas es el desplazamiento que se juega en los términos de la obsolescencia y la extinción.

La novela de Havilio se inscribe en un territorio del presente que encarna, de un modo privilegiado, procesos de extinción y de transformación. Digo esto porque el Opendoor que da título a la novela es un pueblo de la provincia de Buenos Aires, desprendido de un antiguo psiquiátrico de puertas abiertas fundado a fines del siglo XIX, la Colonia Nacional Neuropsiquiátrica Domingo Cabred. El pueblo nació del loteo de campos aledaños a la colonia y este origen expone, hay que remarcarlo, una genealogía de mecanismos de control subterráneos al corazón de la geografía rural, un tramado secreto que regula y se proyecta sobre territorios que, se sabe, no son naturales, es decir, libres de la intervención humana. En este territorio antaño periférico se reúnen los personajes de la narración, ellos mismos rebordes, restos, sujetos decantados de existencias múltiples y divergentes.

La novela de Havilio sigue los pasos de una joven que es despedida de la veterinaria en donde trabaja después de la crisis que la golpea tras la desaparición de su pareja (el relato alimenta la sospecha de que la desaparecida se habría lanzado en el Riachuelo, es decir que esa sombra que la protagonista ve caer desde un puente en la zona de La Boca es, posiblemente, su amiga desaparecida). Sin dinero ni alojamiento, la joven se muda 
de Buenos Aires a Opendoor, con un hombre de campo, el viejo Jaime, a quien conoció casualmente en ocasión de tratar a su caballo moribundo. A partir de ese momento la joven inicia en Opendoor una insólita vida pseudo-rural. Se convierte en la pareja de Jaime, que hace trabajos de jardinería en el psiquiátrico, y simultáneamente entabla relación con una chica del pueblo, Eloisa, una personalidad osada, que se convierte en su cómplice sexual y con la que también comparte la experiencia con drogas. Como se desprende, la novela desestructura oposiciones tradicionales en relación con el campo y la ciudad, establece una zona transurbana o transrural en que los personajes se deslizan, libres de definirse en relación con los espacios y con estereotipos que, con cierta sorna, son aludidos, pero solamente para ser de inmediato descartados, poco pertinentes para esta comunidad lábil que se forma alrededor de Opendoor: "Jaime habla un lenguaje antiguo, del interior, a veces me olvido que es un hombre de campo y que yo debo ser, a esta altura, la mujer de un hombre de campo. Una nueva generación de mujeres de campo" (Havilio 2014: 126).

Los tópicos de la conducta urbana o rural, los tiempos del pueblo y de la ciudad, los parámetros culturales, todo esto se activa en las experiencias de los personajes según una resolución azarosa o por completo arbitraria. Los personajes no expresan una subjetividad propia, en términos individuales, más bien actúan a partir del encuentro de su subjetividad con un panorama de sensibilidades contemporáneas, y de esa pugna nace la acción. Así sucede en la escena en que la protagonista aborta la posibilidad del encuentro sexual con el secretario del juzgado diciéndole que es virgen. A los pocos segundos, él entiende la broma, pero esa respuesta ya ha desvirtuado el tono de la situación y los llevará a dormir "en cuartos separados, como un matrimonio antiguo" (Havilio 2014: 121). Tal como lo plantea, entre otros, Nicolas Bourriad, es inconducente dirimir en el arte contemporáneo qué es producto y qué es residuo, porque el residuo y el material desplazado, reutilizado y redefinido es el material por excelencia de la producción artística contemporánea: "el lugar donde se desarrollan las negociaciones fronterizas entre lo excluido y lo admitido, entre el producto y el residuo. El término exforma designará aquí a la forma atrapada en un procedimiento de exclusión o de inclusión. Es decir, a todo signo transitando entre el centro y la periferia, flotando entre la disidencia y el poder" (Havilio 2014: 11). Opendoor se compone de esos residuos, de esas coexistencias de referentes culturales, sus personajes pueden golpear las palmas para llamar como se supone que se hace en el campo, pero también zambullirse en un desenfrenado raid de drogas y escenas orgiásticas. Pueden disfrutar de comer frutos de los árboles, pero viven en un territorio que también es de pasaje, pueden frecuentar a los gitanos rumanos o que la protagonista halle, intempestivamente, al secretario del juzgado en el neuropsiquiátrico cuando este va a visitar a su hermano gemelo. Este ensamblaje de vestigios y actualizaciones no se inclina, sin embargo, ante el registro melancólico o una ambientación fosilizada como la que expone Villar Rojas. Muy al contrario, Opendoor y sus personajes habitan un borde desde el que todas las opciones vitales son posibles y potenciales, vibran con una vitalidad incomparable.

La efímera comunidad que allí se reúne abarca distintas generaciones, personalidades y oficios: desde un exgaucho devenido albañil y cuidador del vivero del psiquiátrico 
hasta jóvenes en busca de experiencias intensas, una preadolescente promiscua y ansiosa, gitanos rumanos, un tímido y apocado empleado de juzgado y una bibliotecaria paralítica de conducta imprevisible. En ese entorno, la ruralidad aparece removida de los recursos económicos ligados al territorio, por eso el exgaucho se recicla como albañil y quienes sobreviven en el pueblo se refugian en actividades de servicios (atención de la biblioteca, almacén, trabajos para el psiquiátrico y otros). En el abismo de la crisis rural que enmarca el relato, el pueblo y los ranchos acentúan su carácter de periferia urbana, es decir territorio, economía y forma de vida errática, incluso inexplorada. En su incesante ir y venir del campo a la ciudad, o del campo al pueblo, los personajes dibujan un tránsito que se define más por las comunidades e individuos que encuentran, circunstancialmente, en cada lugar, que por formas de vida, circuitos económicos o experiencias ontológicas ligadas a uno u otro espacio.

Este solapamiento de territorios se refracta en la coexistencia de temporalidades que la novela engrana y se extiende, en primer grado, a la comunidad transgeneracional que se forma, independiente de roles u ordenamientos generacionales. Además, el encuentro de temporalidades - subrayado también aquí por órdenes de obsolescencia, residuo y reutilización- no solo se inscribe en pautas culturales o materias de experiencia, involucra también el concierto de tecnologías levemente anacrónicas con que interactúan los personajes: desde la camioneta lenta y calamitosa de Jaime hasta la moto del hermano de Eloísa, las computadoras y las máquinas de escribir del juzgado, los contestadores automáticos, el fax, la computadora y el walkman. Este conjunto establece una periodización desfasada, un ajuste leve en relación con un presente que es el del lector (la primera edición de la novela es de 2006). La computadora, por ejemplo, falla, es vieja, pero sirve, e incluso su carácter anticuado la convierte en sujeto de expresiones o sensibilidades imprevistas:

El monitor es de los que se veían antes, catorce pulgadas, abombado, la imagen titila y de tanto en tanto se le van los colores, y vuelven, de golpe. El teclado suena mucho, y parejo. Todas las letras iguales, la $a$ igual a la $l$, la $j$ a la $s$, igual a la barra de espacio, a la coma, al punto, al guion bajo, al paréntesis, todo igual. Es un lenguaje cacofónico. Solo cambian la intensidad y el ritmo (Havilio 2014: 181).

De alguna manera, como en las obras de Villar Rojas, los períodos se sedimentan tanto en las tecnologías como en la hibridez de las costumbres sociales y los horizontes de acción de los distintos personajes: los fantasmas de los fundadores del psiquiátrico de Opendoor coexisten con la libertad sexual, la costumbre de aplaudir a la hora de la siesta, la marihuana, la vida de pueblo y la ketamina.

$\mathrm{Al}$ independizarse el orden de la narración de un principio temporal o espacial, se interna, por el contrario, en una condición de coexistencia, ${ }^{1}$ un universo de empatías

\footnotetext{
${ }^{1}$ La condición que Jean Luc Nancy en La ciudad a lo lejos vincula con el carácter original, social, de la polis, su vocación de circulación, tráfico, deriva, también encuentro, coexistencia y comercio.
} 
y vínculos que incluso atraviesan las especies, como es la identificación extrema entre los dos Jaimes, el caballo y el hombre, o entre Yasky y su hermano Julio: "El otro, de remera blanca con la foto de un velero en el medio, es, más pálido y despeinado, la copia de Yasky: la misma cara redonda, el porte clásico, el cuello corto, ni gordo ni flaco, peludo, Yasky en loco" (Havilio 2014: 102-3). No hay aquí ningún universo de dobles sino de devenires posibles que, como flechas vitales, adquirieron esta u otra configuración. Además, en tanto vecinos de Opendoor, la relación de los personajes con el psiquiátrico es enigmática. Los vecinos podrían ser, por qué no, enfermos externalizados en un establecimiento que se concibió de puertas abiertas pero con una calculada distribución: por un lado, están "las casas de los enfermos que deben estar en permanente vigilancia o en un aislamiento pasajero; del otro lado, la colonia de las puertas abiertas y del trabajo agrícola. Ningún muro restringe el horizonte, nada que limite la ilusión de la libertad absoluta" (Havilio 2014: 128).

La incertidumbre sobre la condición de los habitantes de Opendoor se mantiene a lo largo del relato: ¿`No serían, acaso, actores de una experimentación social desprendida a futuro de la colonia, seres alienados y expuestos una nueva regulación, en apariencia más libre, de los cuerpos y de las existencias? Como operación literaria, esta indecidibilidad estimula la exploración de vidas potenciales, virtuales en el sentido deleuzeano, por poseedoras de una potencia de acción que busca inventarse a sí misma. Vittoria Borsó propone leer en la literatura esta noción de Deleuze en clave de biopoéticas: "La dinámica de la escritura configura un espacio en el que toman cuerpo dichas excedencias. Polifonías, ambigüedades, paradojas y otras técnicas dan aliento a la dynamis del viviente como un proceso abierto, con el poder de transformarse y estar en continua metamorfosis" (Havilio 2014: 23). En otro plano, los mecanismos de regulación social y la reflexión sobre la demencia, la libertad y el régimen de vida de los locos que la protagonista encuentra en los documentos fundadores de Opendoor constituye una suerte de melodía de fondo en el relato, una distorsión por la que esas mismas categorías y mecanismos de control se proyectan sobre las conductas de los personajes no para administrarlas o calificarlas, sino para constituirlas en tensión respecto de los parámetros del siglo anterior.

La novela remeda el tópico, ya clásico, del sujeto que inmerso en la naturaleza germina con una esencia humana renovada, pero en este caso el entorno rural-periférico promueve tanto una experimentación de nuevas temporalidades como experiencias extremas que habitualmente conciernen al ámbito urbano. La mujer protagonista se abandona a la concomitancia con este medioambiente híbrido en un proceso de despojamiento de sí: sueña con "sapos, polleras, orgías, y caballos" (Havilio 2014: 175). No se trata para ella de modificarse con el entorno bajo algún tipo de aprendizaje; al contrario, opta por abandonarse a un estado de vaciamiento, un despojarse que David Le Breton identifica como un rasgo propiamente moderno y contemporáneo, una respuesta a las presiones del capitalismo global sobre el individuo que es impulsado a una práctica constante de reinvención de sí, y que en la novela, en particular, prospera según un registro ligado a la droga o a la sexualidad desbordada: 
Me paso el día sola, no me muevo y a veces, de tanto fumo, como le dicen en el campo, se me va la cabeza, pierdo noción, me cuelgo. Todo se vuelve oscuro, denso, gelatinoso, todo pasa por mis dedos que me arañan la piel, fuerte, con la ilusión de atravesar la carne, y yo ahí dejo de ser, dejo de actuar, me dejo llevar, acostada, parada, la panza presionada contra la pileta del baño, de loza gruesa, fría, pampeana, y no paro, me río sola, bailoteo, tiemblo un poco, y no paran los dedos, como si no fueran míos, de frotar el clítoris, el botón, de enroscar los pelos que cubren la concha $[. .$.$] y el olor a campo, a pasto húmedo, a luciérnagas, a parra$ seca, a ligustrina recién rebanada, y a los frutales, nísperos, quinotos, higos, el olor a barro mojado, el olor a polen, todos esos olores, tan patrios, se mezclan con los míos, hirviendo, como los de una gata en celo, una gata loca, desquiciada, que no puede más, que se arrastra, que acaba por enésima vez, a lo bestia, con los ojos turbios, deshecha de tanta paja (Havilio 2014: 174-5).

La pulsión sexual acoplada a la sensorialidad del campo regresa aquí exacerbada, en una parodia descentrada de los olores patrios que son los de la "gata en celo", "desquiciada", en una animalidad que atraviesa en algún u otro momento a todos los personajes sea por el desenfreno sexual o por otros conductas: "Amanecí con vómitos. Jaime, que está acostumbrado a Boca que cuando se pasa de vino y carne se pierde por ahí, un poco a campo abierto, se mete los dedos y le devuelve todo a la tierra, no le dio importancia" (Havilio 2014: 154).

Sin embargo, sería falso afirmar que hay aquí una renovación del relato del espíritu salvaje asociado a la naturaleza, que infecta y se introduce en los personajes. La narración juega con ese registro, efectivamente, pero las arbitrariedades de las conductas y de las causalidades que operan la secuencia narrativa relativizan esta línea de lectura. Además, el ámbito seudo rural extrae a la protagonista del orden del sujeto productivo:

Hay noches que me tiro en el pasto boca arriba y el cielo me deja tonta. Es una sensación que se prolonga por unos minutos y que después se deshace a fuerza de distracción o porque se vuelve triste, en un segundo voy y vengo de esa suerte de asombro en estado puro a una especie de introspección complicada. Son cosas que pasan más en el campo que en la ciudad, cosas que le pasan a la gente de la ciudad cuando está en el campo (Havilio 2014: 149).

La protagonista se sumerge, entonces, en un espacio ligado al goce, el mismo que la impulsa al despojamiento, como un nuevo Bartleby, pero femenino e intensamente erotizado. El milagro es que ese despojamiento posibilita una existencia cabal, incluso el nacimiento del hijo que tampoco es considerado como ninguna conclusión más o menos afortunada, pero sí como prueba de esta vitalidad sin mengua, de una potencia capital. Con una felicidad dolorosa, la novela de Havilio se vuelca hacia rangos de experiencia que evaden redes de contención y administración del tiempo y del trabajo, desenvuelve en su lugar una 
especie de vida cotidiana sin guión previsto pero que, como señala Jonathan Crary en su estudio del capitalismo tardío, conserva un potencial de rebeldía frente a la subdivisión y proliferación de los tiempos productivos de la actividad social: "Lo cotidiano era la vaga constelación de espacios y tiempos fuera de lo que estaba organizado e institucionalizado alrededor del trabajo, el consenso y el consumo... Debido a su resistencia a la captura y a la dificultad de volverse útil, lo cotidiano fue considerado por muchos como un núcleo con potencial revolucionario (Crary 2015: 95).

En la novela, el orden de lo socioeconómico determina en alto grado los tránsitos de los personajes: la protagonista es despedida y se queda sin casa, por eso se establece en Opendoor; Eloísa se va del pueblo de la mano de un novio con plata, Jaime es un trabajador fuera del sistema, que se refugia en la actividad informal. ¿Constituye esta mini-comunidad un escudo de protección para las precariedades económicas y afectivas de los personajes? Por una parte, sí, efectivamente, pero lo que prima es una aceleración vital donde se reproduce la aceleración del capitalismo global -el cambio de trabajo, de identidades, de vínculos, de alianzas - pero abriéndose a un orden cuya materia es lo cotidiano invisible. La narración insiste en un relato de frases cortas, en tiempo presente. Hay que recordar que el presente es el tiempo de la inmediatez, que explicita una condición de coexistencia entre la narración, el narrador y el lector. La elección de esta forma textual pliega los tiempos de la obra con los tiempos de la lectura, subrayando la continuidad entre la situación de enunciación-recepción y la escena que se narra. Justamente, una parte importante de los relatos contemporáneos del realismo más reciente involucran una puesta en primer plano de la acción y un retroceso de la dimensión explicativa o evaluativa de las narraciones (Contreras 2006), lo que, en efecto, también en Opendoor se comprueba. Pero en esta novela en particular, hay otras consecuencias que interesa destacar. Al prescindir de explicaciones, Opendoor fuerza el efecto de espontaneidad y azar, finalmente la condición de esa potencialidad vital que moviliza el relato y que, se diría, orquesta un sistemático escamoteo de las causalidades.

En el capítulo veinticinco se produce una situación que ejemplifica de manera magistral lo que acabo de señalar: Jaime está furioso por la relación que la protagonista mantiene con la adolescente Eloísa. Bajo una rabia creciente, le indica a su mujer que hay una rata en el salón en donde están, toma una escopeta y comienza a disparar para todas partes en lo que parece un fenómeno alucinatorio que, además, pondría de manifiesto su estado de locura controlado y, subsidiariamente, su vínculo equívoco con el psiquiátrico de puertas abiertas. Sin embargo, a último momento, una rata cae sobre el hombro de la protagonista y Jaime dispara a quemarropa contra ella: "La verdad es que estuvo muy poco encima mío, una fracción de segundo que en el momento me pareció un ańo y medio. El tiempo justo para mirarme a los ojos, después saltó" (Havilio 2014: 132). Los animales en la novela miran a los ojos, también ellos son agentes de decisión y acción. Como los personajes, son cuerpos-en-situación, seres en relación con los otros, pero en relaciones que trastocan ordenamientos sociales admitidos.

En Nunca fuimos modernos, Bruno Latour propone que la red de prácticas y sentidos que la modernidad desglosó en ordenes de naturaleza, cultura y discursos, no fue, o no es, 
más que una impostación que en la actualidad regresa de su error de la mano de los híbridos o cuasi-objetos o cuasi-personas (acontecimientos que fuerzan a considerar la existencia de una red discurso-naturaleza-política (cultura-sociedad), los fenómenos ecológicos, para dar un ejemplo). "Es nuestra culpa", pregunta- "si las redes son a la vez reales como la naturaleza, narradas como el discurso y colectivas como la sociedad?” (Latour 2007: 22). En este modelo que plantea Latour, el concepto moderno del tiempo que deja atrás y elimina lo anterior se juzga falso, y la retórica de lo que retorna aparece como una fabulación específicamente moderna para nombrar aquello que siempre estuvo: "la reconstitución histórica y el arcaísmo son dos de los síntomas de la incapacidad de los modernos para eliminar lo que sin embargo deben eliminar para tener la impresión de que el tiempo pasa" (Latour 2007: 105)². Desde esta perspectiva, los repertorios de pulsión vital (lo que Borsó denomina la dynamis del viviente) que la novela recorre, sumados a los solapamientos temporales y espaciales, a la coexistencia de tecnologías actuales y anacrónicas y a los divergentes horizontes de experiencia de los personajes, todo ello contribuye, justamente, al refuerzo de redes de continuidad entre naturaleza, cultura, experiencia y discurso.

\section{ESPECTÁCULO, RECORTE Y PERSPECTIVA}

Las puertas abiertas de la novela de Havilio reenvían hacia un abanico de sentidos aludidos, son puertas abiertas entre el espacio rural y el urbano, lo más evidente, o puertas abiertas a la irrupción del cuerpo femenino en el espacio rural, pero es sustancial subrayar otros tránsitos que se evidencian en relación con la distancia de la percepción y la definición de conjunto que la novela entrama. En la escena inicial de la novela, donde la protagonista ve a una persona lanzarse desde la altura del puente y no puede afirmar con certeza si se trata o no de su pareja, se juega, sobre todo, un problema de distancias, de focalización y reconocimiento. En el caso de la chica que se tira del puente, se precisaría un acercamiento; pero para otros fenómenos y experiencias que la novela invoca solamente una mirada más amplia, que incorpore otros elementos, puede visibilizar, por ejemplo, la relación insinuada entre los personajes y el psiquiátrico, una relación que la protagonista va descubriendo paulatinamente porque en un inicio ni siquiera sabe que Opendoor es, también, el psiquiátrico.

En este punto, la novela nos arroja hacia múltiples interrogantes: ¿Qué tan cerca debemos estar para descubrir los detalles de lo evidente y qué tan lejos para comprender los alcances del conjunto? ¿Cuáles son los saberes o las pertinencias que deben considerarse en una situación compleja? En la escena en que Jaime dispara a la rata: ¿Qué es lo que Jaime ve y el lector no percibe? ¿O cuál es la inflexión emocional -que evidentemente Jaime desconoce de sí- pero que permite reconocer en esa rata una encarnación de su

\footnotetext{
${ }^{2} \mathrm{Al}$ respecto, y tal como lo asume Johannes Fabian (2002), ver el pasado como anterior y no como coexistencia es un mecanismo ya clásico, por ejemplo, en relación con los pueblos originarios. La antropología clásica se funda en estos términos generales de "negación de la simultaneidad".
} 
propia locura y enojo? O, todavía más: ¿debiéramos seguir la trama de Opendoor en el pueblo, y en las idas y venidas a la capital o, por el contrario, se requiere un marco más amplio, que incluya la sombra que el psiquiátrico proyecta sobre la condición psíquica de los protagonistas? La vida de los personajes sugiere planos superpuestos, mesetas de existencia que la novela solo es capaz de sugerir, vacíos de información y de certezas, la de la pareja de la protagonista, por ejemplo, cuyo cuerpo finalmente se encuentra, pero que ha muerto apenas unos días antes, es decir que durante todo el desarrollo del relato ha llevado una vida paralela de la que nada sabremos incluso al terminar la lectura. De ese modo, en la novela, recorte y amplitud son dos movimientos que se corresponden, y solamente en el vaivén de uno a otro se vislumbra -más no sea- una comprensión de experiencias plenas. El orden del recorte y de la amplitud, aunque de prerrogativa visual, supone en este punto, por derecho propio, una cuestión atinente a la complejidad de las existencias. Por eso mismo, si la cordura o locura de los personajes de la novela está puesta en duda, la narración extrema estas nociones cuando se abre a una galería de situaciones complejas: el sexo descontrolado en Eloísa, la dislocación del yo en la protagonista, el carácter oscuro, pero ajeno a toda introspección, de Jaime, incluso el posible fantasma de Aída, la joven desaparecida y tal vez muerta cuya presencia intentan invocar:

Ahora el fantasma habla, dice cosas, incongruentes, a veces se queja, otras se ríe, es una risa forzada, pasada de alcohol. Hay algo en el timbre de voz cambiado, pero es ella, como de carne y hueso. Intento ignorarla, convencerme de que es pura imaginación, un juego demente, perverso, pruebas a las que me somete el inconsciente para mantenerme alerta, y sin embargo es tan cierto, tan real, que no quiero ni pensar en animarme a estirar el brazo: ¿y si la toco? (Havilio 2014: 160).

La cercanía es, efectivamente, una entrada en la intimidad de los cuerpos, un reconocimiento de la piel o de las voces en la oscuridad, un acercamiento con los otros sin la mediación de las intenciones o los pensamientos, algo que simplemente es.

En el desenlace de la novela, los personajes emprenden un paseo de caza por la montaña y encuentran lo que inicialmente suponen luces no identificadas, tal vez un ovni. La confusión se aclara cuando, al aproximarse, descubren que se trata de la filmación de una película publicitaria con indios. En suma, de nuevo se aplica un problema de focalización. En la lejanía, las luces los ciegan y creen reconocer ovnis, pero al acercarse identifican un set de filmación. La alusión a las formas de representación ya se había establecido en una escena anterior, cuando, recién despierta en el hospital, la protagonista confunde con un paisaje natural el papel decorado que representa un pinar y un lago. La escena de las luces finales recalca el carácter construido intrínseco a toda percepción, al mismo tiempo que acentúa un guińo al orden de la representación que juega cualquier obra artística y, en consecuencia, su incierta relación con la verdad.

Pero podemos arriesgar otra reflexión guiada por los objetos de Villar Rojas: todo modo de vida puede ser potencial (es decir, futuro, deriva e imaginación, otras formas de 
nombrar a lo que se opone a lo "actual"), e incluso lo potencial es fósil de otro estado. Las obras de Villar Rojas y la novela de Iosi Havilio establecen un tiempo de interconexión y constituyen dispositivos que escenifican las múltiples puertas. En el desenlace de Opendoor, el parque temático de las falsas tiendas de los indios no es opuesto sino adyacente al lugar mismo en que las dos mujeres se reencuentran y abrazan: "Nos besamos como dos adolescentes, devorándonos a escondidas, contra el tronco de un ombú gigante. Me siento feliz" (Havilio 2014: 197). Así se cierra la novela, en una escena en que se superponen y coexisten dos tiempos, dos estados y dos materias: la crepuscular y artificial escena de la filmación con el encuentro de las pasiones y los cuerpos.

También en las instalaciones de Villar Rojas, las tensiones del pasado y del futuro, de lo más innato y de lo más construido, patentizan la inviabilidad de discernir bajo esos términos. El recorte y la amplitud, las puertas abiertas, especies de vasos comunicantes entre categorías y estados, ligan en Opendoor razón y locura, edad joven y senectud, cultura y naturaleza, estados latentes y potencia vital. Por último, se trata de entender que tanto la novela de Havilio como las obras de Villar Rojas funcionan como dispositivos que involucran al lector y al espectador, son "contraproductos" porque invocan aquella singularidad de la experiencia que demanda Bernard Stiegler, bajo el compromiso de reintroducir experiencias disruptivas en un contexto de homogeneización cultural. Las puertas abiertas trastornan la temporalidad, pero también disputan subjetividades que la modernidad concibió como autónomas, centrales a un sujeto que, abandonado a sus propias potencias, de repente se descubre poroso respecto de los otros, pero también en una relación vigorosa y más dinámica con la cultura, la naturaleza, los objetos y los discursos.

\section{OBRAS CITADAS}

Borsó, Vittoria. 2016. "Más allá de la biopolítica. Epistemología y estética de la vida". Telar 16: 18-41.

Bourriaud, Nicolas. 2015. La exforma. Buenos Aires: Adriana Hidalgo.

Contreras, Sandra. 2006. "Discusiones sobre el realismo en la narrativa argentina contemporánea”. Orbis Tertius 11 (12): 1-15.

Crary, Jonathan. 2015. 24/7. El capitalismo tardío y el fin del sueño. Buenos Aires: Paidós.

Deleuze, Gilles. 1996. Crítica y clínica. Barcelona: Editorial Anagrama.

Fabian, Johannes. 2002. Time and the Other: How Anthropology Makes Its Object . Columbia: Columbia Univers. Press.

Harman, Graham. 2015. "Bruno Latour, el señor de las redes". En: Harman, Graham. Hacia el realismo especulativo. Ensayos y conferencia. Buenos Aires: Caja negra. 39-69.

Harman, Graham. 2015. "La teoría de los objetos en Heidegger y Whitehead". En: Harman, Graham. Hacia el realismo especulativo. Ensayos y conferencia. Buenos Aires: Caja negra. 13-38.

Havilio, Oisi. 2014. Opendoor. Buernos Aires: Entropía. 
ESTUDIOS FILOLÓGICOS

Latour, Bruno. 2012. Enquete sur les modes d'existence. Une antropologie des Modernes. Paris: La Découverte.

.2007. Nunca fuimos modernos. ensayo de antropología simétrica. Buenos Aires: Siglo XXI.

Le Breton, David. 2015. Disparaître de soi. Une tentation contemporaine. Paris: Métailié.

Nancy, Jean-Luc. 2013. La ciudad a lo lejos. Buenos Aires: Manantial.

Speranza, Graciela. 2017. Cronografias. arte y ficciones de un tiempo sin tiempo. Barcelona: Anagrama.

Stiegler, Bernard. 2004. La técnica y el tiempo III. El tiempo del cine y la cuestión del malestar. Hondarribia: Hiru. 
